\title{
Vorwort zur ersten Auflage
}

Das vorliegende Buch, das in den Jahren 1944-46 geschrieben wurde und eine Ergänzung meiner „Tierpsychologie“ darstellt, ist ein selbständiges Ganzes, so daß sein Verständnis nicht die Kenntnis des ersten Teils des Werkes voraussetzt. Ohne den Anspruch auf eine erschöpfende Behandlung des Problems zu hegen, wollte ich in meiner Arbeit die zeitgenössischen Anschauungen über die Psychologie der Affen darlegen. Die einschlägige Literatur ist sehr umfangreich und äußerst ungleichmäßig; auf vielen wichtigen Gebieten aber verfügen wir nur über fragmentarische Kenntnisse. Besonders verhängnisvoll wirkt sich die Unkenntnis der natürIichen Lebensbedingungen der Affen aus, ein Umstand, der ein klares Verstehen des Verhaltens der Tiere bei Laborexperimenten erschwert. Nichtsdestoweniger ist dies ein ausgedehntes und viel behandeltes Forschungsgebiet, das in der Weltliteratur einen ansehnlichen Platz einnimmt, für unseren Büchermarkt jedoch völlig neu ist. Dieser Umstand rechtfertigt die Herausgabe dieses Buches.

Unter den Autoren, die sich mit der Tierpsychologie befassen, herrschen zwei Tendenzen vor. Die einen lieben die Tiere und möchten ihnen möglichst viele menschliche Merkmale zuschreiben. Die anderen verhalten sich den Tieren gegenüber gleichgültig und neigen dazu, deren Seelenleben allzu niedrig einzuschätzen. Möglich ist jedoch auch ein objektiver Standpunkt, der, unabhängig von Sympathie oder Antipathie, allein von dem Wunsch diktiert ist, exakt und kritisch festzustellen, welches die tatsächlichen Verhaltensmerkmale eines Tieres sind.

Die Entstehung des Werkes verdanke ich der Zuvorkommenheit vieler, denen ich hiermit meinen Dank ausdrücken möchte. Besonders verpflichtet bin ich Prof. Rubinstein für seine Erlaubnis, die reichhaltige Bibliothek des Psychologischen Instituts in Moskau zu benutzen, Prof. NESTURCH für eine Reihe von Aufnahmen aus dem Archiv des Anthropologischen Museums (Abb. 1, 2, 3, 4, 5, 6, 8, 10,11) sowie Frau LAdYGINAКонтs für ihre freundliche Erlaubnis, einige vortreffliche Aufnahmen über den emotionellen Ausdruck des Schimpansen zu reproduzieren (Abb. 20, 21, 22, 23, 24, 25).

M o s k a u, den 26. März 1946

Jan Dembowski 